\title{
Phase retrieval in near-field measurements by array synthesis
}

\author{
Wu, Jian; Larsen, Flemming Holm
}

Published in:

Antennas and Propagation Society International Symposium

Link to article, DOI:

10.1109/APS.1991.175129

Publication date:

1991

Document Version

Publisher's PDF, also known as Version of record

Link back to DTU Orbit

Citation (APA):

Wu, J., \& Larsen, F. H. (1991). Phase retrieval in near-field measurements by array synthesis. In Antennas and Propagation Society International Symposium (Vol. Volume 3, pp. 1474-1477). IEEE. https://doi.org/10.1109/APS.1991.175129

\section{General rights}

Copyright and moral rights for the publications made accessible in the public portal are retained by the authors and/or other copyright owners and it is a condition of accessing publications that users recognise and abide by the legal requirements associated with these rights.

- Users may download and print one copy of any publication from the public portal for the purpose of private study or research.

- You may not further distribute the material or use it for any profit-making activity or commercial gain

- You may freely distribute the URL identifying the publication in the public portal

If you believe that this document breaches copyright please contact us providing details, and we will remove access to the work immediately and investigate your claim. 
PHASE RETRIEVAL IN NEAR-FIELD MEASUREMENTS BY ARRAY SYNTHESIS

\author{
J. Wu, F. Holm Larsen \\ Technical University of Denmark \\ Building 348, EMI, DK-2800, Lyngby, Denmark
}

\begin{abstract}
The phase retrieval problem in near-field antenna measurements is formulated as an array synthesis problem. As a test case, a particular synthesis algorithm has been used to retrieve the phase of a linear array.
\end{abstract}

\title{
Introduction
}

Microwave holographic metrology has been introduced as a useful antenna measurement technique in the 70's [1][2]. Recent developments of the technique allow near-field measurement to be carried out by measuring the field amplitude only on two surfaces which have a sufficient separation in distance.

Therefore the phase on one of the surfaces can be retrieved by the additional information measured on the other surface. The most popular method has been the Gerchberg-Saxton error reduction algorithm where a Fourier transform is used between the aperture field and the far field. Also the Fourier transform can be used to iterate between two planar surfaces. Each time after the transformation the measured field amplitude is used to replace the result of the Fourier transformation. Although it is efficient and powerful by using FFT, a paper [3] did complain very recently that a crucial role is played by the availability of some kind of extra information concerning the near-field and/or the radiating system, in order to avoid the trapping of the iterative procedure. Another approach [4] is to use gradient minimization scheme on the functional

$$
\Phi(E)=|||E|^{2}-m^{2}||^{2}+|||T(E)|^{2}-M^{2}||^{2}
$$

where $m$ and $M$ are the measured two amplitudes on two surfaces, $T$ is the linear operator which represents the relation between the field on the two surfaces in the near-field. Therefore $\mathrm{E}$ is the only unknown which has to be adjusted in order to minimize the total error. It has been claimed that this approach does not need extra information apart from the two amplitudeonly measurements, but from array synthesis theory it is well

91CH3036-1/0000-1474 \$1.00 @1991 IEEE 
known that gradient algorithms are sensitive to local solutions.

New Formulations

Similar to the second approach mentioned above, a new formulation is proposed. Refering to (1), the first term is actually equal to zero if the minimization algorithm can handle the amplitude constraint separately. For such algorithms, the functional becomes

$$
\Phi(E)=\sum_{j=1}^{n s}|||T j(E)|^{2}-M j^{2}||^{2}
$$

subject: $\quad|| E||=\mathbf{m}$

where $n s$ is the number of sampling points at the second measurement surface. This new functional shows that the problem is equivalent to a power pattern synthesis problem with least square optimization criteria under a source amplitude constraint. For the power pattern synthesis problem of an array antenna, it is known that other criteria can be used such as minimax [5] or maximin [6]. The difference between the pattern synthesis and the phase retrieval is that in the later case, since the desired pattern $(M)$ is originally generated by the source $(E)$, the result do exist to realize (M) precisely and the result probably will be unique. Therefore different optimization criteria will give the same result. The minimax and the maximin formulations of the problem are

$$
\begin{aligned}
& \min _{E}\left\{\max _{1 \leq j \leq n s}|||T j(E)|^{2}-\mathrm{Mj}^{2}||\right\} \\
& \text { subject: }|| \mathrm{E}||=\mathrm{m} \\
& \max _{\mathrm{E}}\left\{\min _{1 \leq j \leq n s}|\mathrm{Tj}(\mathrm{E}) / \mathrm{Mj}|\right\}
\end{aligned}
$$

or

subject: $\quad|| \mathrm{E}||=\mathrm{m}$.

At the precise final solution, the object function in (3) will be equal to zero and it will be equal to 1 in (4). Comparing (4) and (3), the object function in (4) deals with the field itself instead of an error 
function. Therefore it may use less computer time, and we also have a powerful maximin optimization algorithm [7] to do the job.

Practical Strategy for Optimization

1.Sampling points selection on the first surface: The first measurement surface is considered as the source in this approach. Depending on the amplitude variation of the source, only some of the measurement sampling points may be selected at the beginning of the optimization. This number can be enlarged progressively to the total number of sampling points at the end of the optimization [4].

2.Sampling points selection on the second surface: The amplitude distribution on the second measurement surface is considered to be the desired pattern as in the pattern synthesis case. There are some points which will play very important roles in the whole procedure. They are the ones which have very small field values and the ones which are in the main lobe or on the peaks of the sidelobes. For the small value points, the optimization can take them as the sidelobe sampling points in the pattern synthesis case to which the values are not allowed to be bigger than the desired ones; and for the big value points, the optimization may take them as the main beam sampling points to which the optimization will try to maximize. Those points on the second surface characterize the whole problem and therefore they are the most useful ones for the optimization.

Test Example

Only a very small simulated test case has been calculated at the time being. The source is a 20 -element linear array. The first measurement surface is simulated as close as possible to the radiation elements which is actually the excitation amplitude distribution of the array. The second surface is very far away from the array and is actually the far field pattern. The phase is retrieved by optimizing the maximin formula (4) using super angle method [7]. It is shown in Fig.1 together with the original one. The amplitude distribution on the first surface is shown in dashed line in the same Fig. More results will be presented at the symposium.

\section{Conclusion}

Although it is too early to say which method is better for the phase retrieval, the conclusion can be drawn, that different possibilities do exist to formulate the problem and lead to different optimization methods. The two way Fourier transformation 
method may be very efficient from a computation time point of view because it uses FFT, but other optimization methods may give better convergence and better results.

\section{Reference}

[1] J.C.Bennet, A.P. Anderson, et al. "Microwave holographic metrology of large reflector antennas", IEEE Trans. AP-24, pp.295-303, 1976

[2] P.F. Scott and M. Ryle, "A rapid method for measuring the figure of radio telescope reflector", Royal Astronom. Soc. Monthly Notices, Vol. 178, pp.539-545, 1977

[3] O.M. Bucci, G. D'Elia, G. Leone and R. Pierri, "Far-Field Pattern Determination from the near-field amplitude on two surfaces", IEEE Trans. AP-38, pp.1772-1779, Nov. 1990

[4] T. Isernia, R. Pierri and G. Leone, "New result in the phase retrieval in near zone", Proceedings of JINA'90, Nice France, pp.589-592, Nov. 1990

[5] P.E. Frandsen and K. Madsen, "Large scale non-gradient minimax optimization", Report No. NI-88-06, Technical University of Denmark, June 1988

[6] R. Li, J. Wu and A.G. Roederer, "The maximin excitation coefficients optimization method for array pattern synthesis", Proceedings of the ESA workshop on antenna technologies, ESTEC, Noordwijk, The Netherlands, Nov. 1989

[7] J. Wu, "Maximin excitation coefficients optimization for array pattern synthesis", Report, No.R417, EMI, Technical

University of Denmark, Feb. 1990

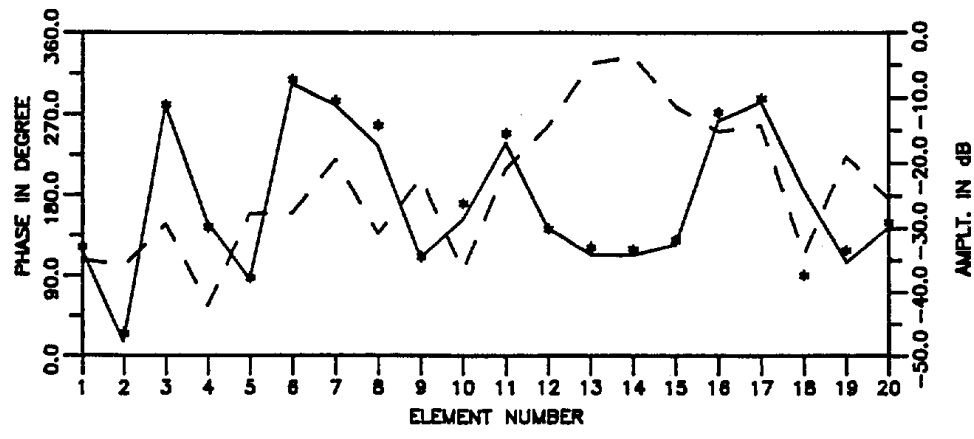

Fig.1 Solid line: original phase. Dots: retrieved phase. Dashed line: Amplitude distribution on the first surface 